\title{
Corrigendum
}

Subsite mapping of Hormoconis resinae glucoamylases and their inhibition by gluconolactone

\section{RICHARD FAGERSTRÖM}

Journal of General Microbiology (1991), 137, 1001-1008

Equation (5) on p. 1003 was incorrect; the correct version is as follows.

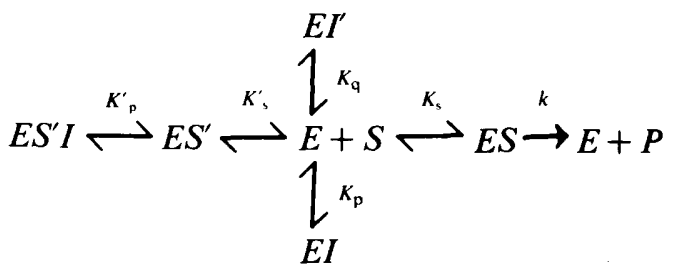

Note that in the original version $K_{\mathrm{p}}^{\prime}$ (located above the first arrow) was printed incorrectly as $K^{\prime}$. 